\title{
Aerobic oxidative desulfurization via magnetic mesoporous silica-supported tungsten oxide catalysts
}

\author{
Wei Jiang ${ }^{1,2} \cdot$ Xiang Gao $^{1}$ - Lei Dong ${ }^{1} \cdot$ Jin Xiao ${ }^{1} \cdot$ Lin-Hua Zhu ${ }^{3} \cdot$ Guang-Ying Chen ${ }^{3} \cdot$ Su-Hang Xun ${ }^{1} \cdot$ Chong Peng $^{4}$. \\ Wen-Shuai Zhu ${ }^{1} \cdot$ Hua-Ming $\mathrm{Li}^{1}$
}

Received: 15 March 2020 / Published online: 1 September 2020

(C) The Author(s) 2020

\begin{abstract}
It is usually difficult to remove dibenzothiophenes from diesel fuels by oxidation with molecular oxygen as an oxidant. In the study, tungsten oxide was supported on magnetic mesoporous silica by calcination to form a magnetically separable catalyst for oxidative desulfurization of diesel fuel. By tuning different calcining temperatures, the catalyst calcined at $500{ }^{\circ} \mathrm{C}$ showed a high catalytic activity with molecular oxygen as the oxidant. Under optimal reaction conditions, the sulfur removal of DBT reached $99.9 \%$ at $120{ }^{\circ} \mathrm{C}$ after $8 \mathrm{~h}$. Furthermore, the removals of 4-methyldibenzothiophene and 4,6-dimethyldibenzothiophene could also get up to $98.2 \%$ and $92.3 \%$ under the same conditions. The reaction mechanism was explored by selective quenching experiments and FT-IR spectra.
\end{abstract}

Keywords Oxidative desulfurization $\cdot$ Molecular oxygen $\cdot$ Magnetic separation $\cdot$ Mesoporous structure $\cdot$ Tungsten oxide

\section{Introduction}

$\mathrm{SO}_{x}$ produced in the combustion of fuel oil leads to severe environmental problems, such as haze and acid rain. To relief environmental pressure, deep desulfurization has

Edited by Xiu-Qiu Peng

Electronic supplementary material The online version of this article (https://doi.org/10.1007/s12182-020-00498-y) contains supplementary material, which is available to authorized users.

$\checkmark$ Chong Peng

pengchong.fshy@sinopec.com

$\triangle$ Wen-Shuai Zhu

zhuws@ujs.edu.cn

1 Institute for Energy Research, School of Chemistry and Chemical Engineering, Jiangsu University,

Zhenjiang 212013, People's Republic of China

2 School of Materials Science and Engineering, Jiangsu University, Zhenjiang 212013, People's Republic of China

3 School of Chemistry and Chemical Engineering, Hainan Normal University, Haikou 571158, Hainan, People's Republic of China

4 Dalian Research Institute of Petroleum and Petrochemicals, SINOPEC, Nankai Road 96 of Lushunkou City, Dalian 116045, People's Republic of China been extensively explored in many countries (Smolders et al. 2019; Li et al. 2018; Afsharpour and Amraee 2017; Zhao et al. 2017a, b). Conventional hydrodesulfurization (HDS) has been widely applied in many industrial fields. However, it is inefficient to remove refractory sulfur components such as dibenzothiophene (DBT) and its derivatives with HDS under mild conditions (Behnejad et al. 2019; Gao et al. 2019; Jiang et al. 2020). In addition, high temperature and high pressure increase the cost of this technology (Shen et al. 2015). To overcome these drawbacks, it is necessary to develop alternative desulfurization technologies. Several desulfurization technologies have been developed, such as extractive desulfurization (EDS) (Wang et al. 2020; Song et al. 2017), adsorptive desulfurization (ADS) (Luo et al. 2019) and oxidative desulfurization (ODS) (Sun et al. 2004; Wu et al. 2017; Xun et al. 2016; Shi et al. 2017; Ren et al. 2018; Hao et al. 2017; Jiang et al. 2019a, b, c, d). Among them, ODS is one of the promising desulfurization approaches because refractory sulfur components could be easily removed with ODS under mild conditions (Bryzhin et al. 2019; Bhadra and Jhung 2019).

Various oxidants have been employed in ODS process, such as hydrogen peroxide $\left(\mathrm{H}_{2} \mathrm{O}_{2}\right)$ (Xun et al. 2019; Jiang et al. 2019a, b, c, d; Jiang et al. 2018), molecular oxygen $\left(\mathrm{O}_{2}\right)$ (Li et al. 2017a, b; Jiang et al. 2019a, b, c, d) and organic peroxides ( $\mathrm{Lv}$ et al. 2019). So far, $\mathrm{H}_{2} \mathrm{O}_{2}$ is commonly used 
as the oxidant for deep desulfurization of fuel. However, $\mathrm{H}_{2} \mathrm{O}_{2}$ has some shortcomings such as strict transportation requirements and high cost. Moreover, $\mathrm{H}_{2} \mathrm{O}_{2}$ as the oxidant has the biphasic problem of the mass transfer, thus decreasing the desulfurization efficiency ( $\mathrm{Li}$ et al. 2019; Zhang et al. 2018). To overcome these shortcomings, $\mathrm{O}_{2}$ has been applied as alternative oxidant in oxidative desulfurization process, due to its low cost, easy availability and high environmental safety.

As so far, several kinds of catalysts have been reported in ODS. For example, polyoxometallates (POMs), such as $\left[\mathrm{C}_{18} \mathrm{H}_{37} \mathrm{~N}\left(\mathrm{CH}_{3}\right)_{3}\right]_{5}\left[\mathrm{PV}_{2} \mathrm{Mo}_{10} \mathrm{O}_{40}\right]$ (Lu et al. 2007), $\left[\mathrm{C}_{8} \mathrm{H}_{17} \mathrm{~N}\left(\mathrm{CH}_{3}\right)_{3}\right]_{3} \mathrm{H}_{3} \mathrm{~V}_{10} \mathrm{O}_{28}$ (Tang et al. 2012), $\left[\left(\mathrm{C}_{18} \mathrm{H}_{37}\right){ }_{2} \mathrm{~N}\right.$ $\left.\left(\mathrm{CH}_{3}\right)_{2}\right]_{5}\left[\mathrm{IMo}_{6} \mathrm{O}_{24}\right]$ (Lü et al. 2010) and $\left[\left(\mathrm{C}_{18} \mathrm{H}_{37}\right)_{2} \mathrm{~N}\left(\mathrm{CH}_{3}\right)_{2}\right.$ ]$_{3}\left[\mathrm{Co}(\mathrm{OH})_{6} \mathrm{Mo}_{6} \mathrm{O}_{18}\right]$ (Lu et al. 2013), have been applied to DBT oxidation with oxygen as the oxidant. Although they showed high desulfurization performance, additional sacrificial agents were required and these catalysts could not be recycled conveniently ( $\mathrm{Li}$ et al. 2017a, b). Other nano-catalysts, such as CNT (Zhang et al. 2014), MOFs (Gomez-Paricio et al. 2016) and graphene-like boron nitride composites (Wu et al. 2016), can also activate $\mathrm{O}_{2}$ for oxidative desulfurization of diesel. Although these heterogeneous catalytic systems could be separated and recovered through filtration, it was cumbersome on an industrial scale. However, magnetic materials allow catalysts to be separated conveniently from the reaction system by the use of an external field (Zhang et al. 2011; Xun et al. 2019).

Herein, magnetic mesoporous core-shell structure catalysts were obtained by calcination at different temperatures. The catalyst calcined at $500{ }^{\circ} \mathrm{C}\left(\mathrm{WO}_{3} / \mathrm{MMS}-500\right)$ showed the best desulfurization performance of DBT with $\mathrm{O}_{2}$ as the oxidant without any sacrificial agent. In addition, other different sulfur compounds including 4-methyldibenzothiophene (4-MDBT) and 4,6-dimethyldibenzothiophene (4,6-DMDBT) were also removed efficiently with the sulfur removal of $98.2 \%$ and $92.3 \%$ after $8 \mathrm{~h}$. After the reaction, the catalyst could be separated with external magnet. Furthermore, a possible mechanism was proposed based on selective quenching experiments and FT-IR spectra.

\section{Experimental}

\subsection{Materials}

All the reagents were used as received without further purification. Iron(III) acetylacetonate $\left(\mathrm{Fe}(\mathrm{acac})_{3}\right)$, benzyl alcohol, oleic acid, oleylamine, cyclohexane, tetraethyl orthosilicate (TEOS), DBT, 4,6-dimethyldibenzothiophene (4,6-DMDBT), 4-methyldibenzothiophene (4-MDBT) and tetradecane $\left(\mathrm{C}_{14} \mathrm{H}_{30}\right)$ were purchased from Sigma-Aldrich. Decalin, phosphotungstic acid $\left(\mathrm{H}_{3} \mathrm{PW}_{12} \mathrm{O}_{40} \cdot 14 \mathrm{H}_{2} \mathrm{O}\right.$, AR grade), cetrimonium bromide (CTAB), benzoquinone (BQ) and tert-butanol (TBA) were purchased from Sinopharm Chemical Reagent Co., Ltd.

\subsection{Synthesis of $\mathrm{Fe}_{3} \mathrm{O}_{4}$ nanoparticles}

Uniform magnetite $\mathrm{Fe}_{3} \mathrm{O}_{4}$ particles were synthesized via the solvothermal method (Sun et al. 2004). In a typical procedure, $\mathrm{Fe}(\mathrm{acac})_{3}(0.53 \mathrm{~g})$, oleic acid $(2.3 \mathrm{~mL})$, oleylamine $(2.3 \mathrm{~mL})$ and benzyl alcohol $(15 \mathrm{~mL})$ were dissolved and magnetically stirred for $30 \mathrm{~min}$. Then, the obtained solution was sealed into a Teflon-lined stainless-steel autoclave and heated at $180{ }^{\circ} \mathrm{C}$ for $10 \mathrm{~h}$. The autoclave was then cooled down to room temperature. The obtained black magnetic particles were washed with ethanol for three times, dried and then dispersed in $13.5 \mathrm{~mL}$ of cyclohexane for the subsequent synthesis step.

\subsection{Synthesis of magnetic mesoporous silica (MMS)}

In order to protect the magnetic core, $\mathrm{Fe}_{3} \mathrm{O}_{4}$ was coated with non-porous $\mathrm{SiO}_{2}$ by a sol-gel growth procedure (Wang et al. 2015). The magnetic mesoporous silica was obtained by a facile calcination method (Deng et al. 2008). $\mathrm{Fe}_{3} \mathrm{O}_{4} @ \mathrm{SiO}_{2}$ $(0.3 \mathrm{~g})$ nanospheres were re-dispersed in a mixture solution containing CTAB $(0.26 \mathrm{~g})$, water $(81 \mathrm{~mL})$, ammonium hydroxide solution $(0.75 \mathrm{~mL}, 28 \mathrm{wt} \%)$ and ethanol $(37.5 \mathrm{~mL})$ by ultrasonication for $30 \mathrm{~min}$. Then, $0.5 \mathrm{~mL}$ of TEOS was added dropwise to the dispersion under mechanical stirring. The reaction was allowed to proceed at ambient temperature for another $8 \mathrm{~h}$. The obtained solid was washed, dried and collected. The MMS was finally obtained by calcining the resulted composite at $400{ }^{\circ} \mathrm{C}$ for $4 \mathrm{~h}$ in muffle furnace.

\subsection{Synthesis of the magnetic catalysts}

MMS (0.07 g), $\mathrm{H}_{3} \mathrm{PW}_{12} \mathrm{O}_{40}$ (HPW, $0.03 \mathrm{~g}$ ) and acetonitrile $(10 \mathrm{~mL})$ were mixed with a magnetic stirrer at ambient temperature for $3 \mathrm{~h}$. The product HPW/MMS was gathered after removing the solvent. Then catalysts were obtained by calcining HPW/MMS at different calcination temperatures $\left(400,500\right.$ and $600{ }^{\circ} \mathrm{C}$ ) for $4 \mathrm{~h}$ with a heating rate of $2{ }^{\circ} \mathrm{C} /$ min in a muffle oven and denoted as HPW/MMS-400, $\mathrm{WO}_{3} /$ MMS-500, and $\mathrm{WO}_{3} / \mathrm{MMS}-600$, respectively.

\subsection{Catalytic activity test}

Model oils were prepared by dissolving DBT, 4-MDBT and 4,6-DMDBT in decalin, respectively, according to the S-content of 500, 200 and $200 \mathrm{ppm}$ (with tetradecane as internal standard). The desulfurization experiments were performed in a $100-\mathrm{mL}$ three-flask with air pump device and condenser. Then, $0.01 \mathrm{~g}$ of catalyst and $20 \mathrm{~mL}$ of model 
oil were added into the flask. Then, $\mathrm{O}_{2}$ was blown into the solution with a flow rate of $100 \mathrm{~mL} / \mathrm{min}$ under magnetic stirring. Quenching experiments of free radicals were conducted by adding BQ and TBA into the reaction system. The sample was taken out and monitored by gas chromatography-flame ionization detector (GC-FID) every $1 \mathrm{~h}$ in 8 -h reaction.

\section{Results and discussion}

\subsection{Charactierization of samples}

Transmission electron microscope (TEM) images of magnetic non-mesoporous silica (MNS) and magnetic mesoporous silica (MMS) microspheres are recorded in Fig. 1a and $\mathrm{S} 1$. It can be seen that $\mathrm{Fe}_{3} \mathrm{O}_{4}$ was successfully coated within $\mathrm{SiO}_{2}$ to keep interior magnetic microspheres from decaying in the subsequent reaction process. The average diameters of synthesized $\mathrm{Fe}_{3} \mathrm{O}_{4}$ and $\mathrm{Fe}_{3} \mathrm{O}_{4} @ \mathrm{SiO}_{2}$ nanoparticles are 14 and $52 \mathrm{~nm}$, respectively. To increase the adsorptive capacity of the catalyst, $\mathrm{Fe}_{3} \mathrm{O}_{4} @ \mathrm{SiO}_{2}$ was encapsulated into mesoporous silica shell. The obtained magnetic core-shell mesoporous nanoparticles have a uniform size with the mesoporous layer around $27 \mathrm{~nm}$ as estimated from Fig. 1a.

Fourier transform infrared spectroscopy (FT-IR) spectra of MMS, HPW/MMS-400, $\mathrm{WO}_{3} / \mathrm{MMS}-500$ and $\mathrm{WO}_{3} /$ MMS-600 are depicted in Fig. 1b. The bands at 1080, 810 and $470 \mathrm{~cm}^{-1}$ are ascribed to the asymmetric stretching vibrations, symmetric stretching vibrations and bending vibrations of $\mathrm{Si}-\mathrm{O}-\mathrm{Si}$, respectively. The peak at $960 \mathrm{~cm}^{-1}$ is assigned to plane stretching vibrations of $\mathrm{Si}-\mathrm{OH}(\mathrm{Ma}$ et al. 2017; Shen et al. 2018). For HPW/MMS-400, the typical peaks at 981 and $890 \mathrm{~cm}^{-1}$ are ascribed to Keggin units of $\mathrm{W}=\mathrm{O}_{t}$ and $\mathrm{W}-\mathrm{O}_{c}-\mathrm{W}$, where $t$ and $c$ represent particular positions (terminal and corner) of different oxygen atoms in Keggin structure (Ciptonugroho et al. 2016). A strong peak around $1080 \mathrm{~cm}^{-1}$ is assigned to $\mathrm{P}-\mathrm{O}$ substituted asymmetric stretching vibration of $\mathrm{Si}-\mathrm{O}-\mathrm{Si}$ bonds. For $\mathrm{WO}_{3} / \mathrm{MMS}-500$, and $\mathrm{WO}_{3} / \mathrm{MMS}-600$, the characteristic peaks at $950 \mathrm{~cm}^{-1}(\mathrm{~W}=\mathrm{O})$ and $815 \mathrm{~cm}^{-1}(\mathrm{~W}-\mathrm{O}-\mathrm{W})$ demonstrate the presence of $\mathrm{WO}_{3}$ (Ding et al. 2015; Zhao et al. 2017a, b). The results confirmed that HPW was immobilized on the MMS surface and decomposed (a)

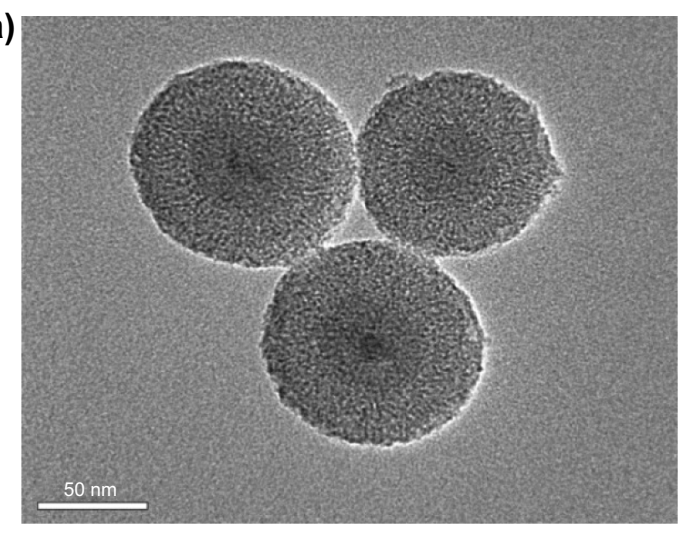

(c)

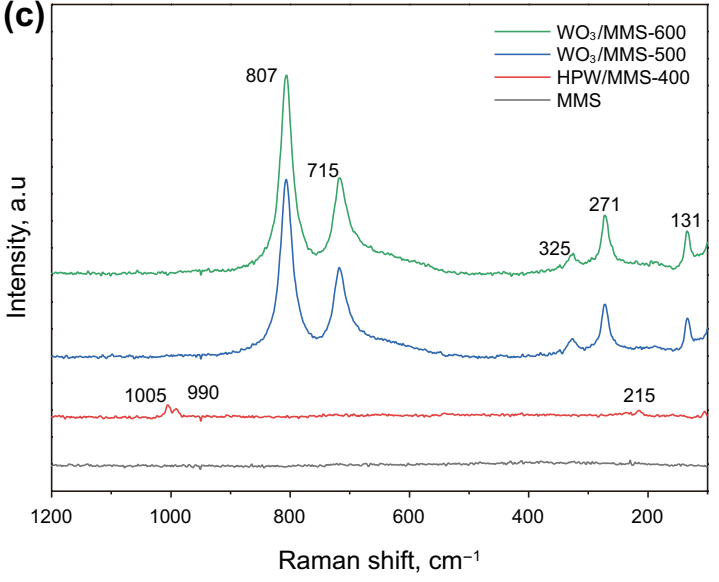

(b)

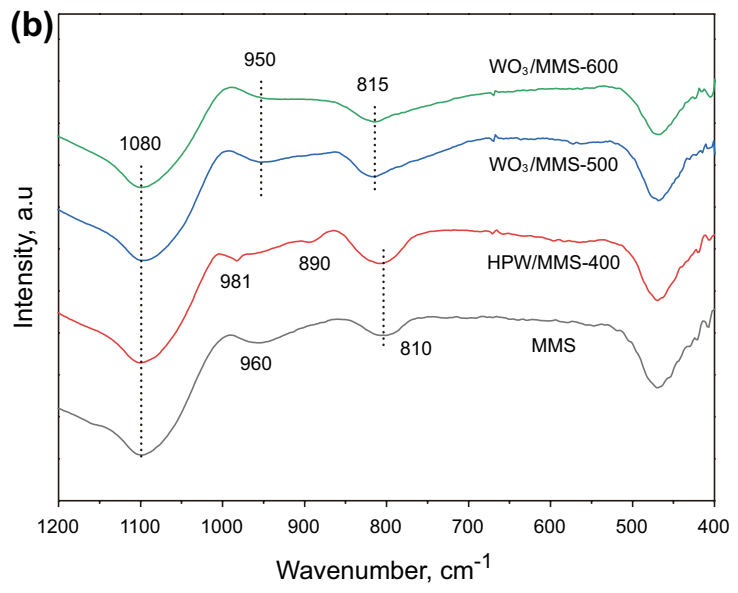

(d)

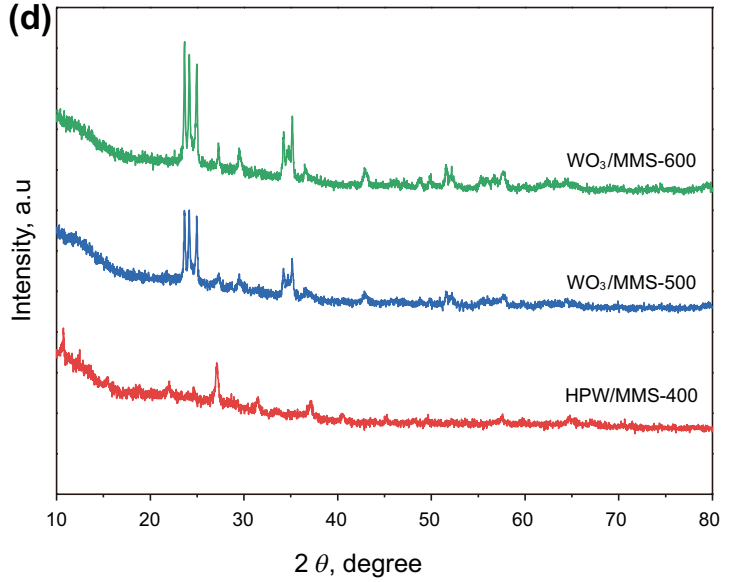

Fig. 1 TEM images of MMS (a), FT-IR spectra (b), Raman spectra (c) and XRD patterns (d) 
into $\mathrm{WO}_{3}$ when calcination temperature was higher than $400{ }^{\circ} \mathrm{C}$.

Raman spectra of the samples were also recorded to explore the structure. As shown in Fig. 1c, MMS has no characteristic peaks. The characteristic peaks at $1005 \mathrm{~cm}^{-1}$ with neighbor bands at 990 and $215 \mathrm{~cm}^{-1}$ are ascribed to the $\mathrm{W}=\mathrm{O}$ symmetric and asymmetric stretching and $\mathrm{W}-\mathrm{O}-\mathrm{W}$ bending mode in the Keggin unit from 110 to $1100 \mathrm{~cm}^{-1}$ (Hamid et al. 2016). This result confirmed that HPW was loaded on the carrier surface and was not decomposed under $400{ }^{\circ} \mathrm{C}$. For $\mathrm{WO}_{3} / \mathrm{MMS}-500$, and $\mathrm{WO}_{3} / \mathrm{MMS}-600$, four typical peaks at $807,715,325$ and $271 \mathrm{~cm}^{-1}$ are assigned to the monoclinic $\gamma$ phase of $\mathrm{WO}_{3}$ (Acharyya et al. 2015; Mehmood et al. 2017). Among them, the peaks at 807 and $715 \mathrm{~cm}^{-1}$ correspond to stretching and bending vibration of $\mathrm{W}-\mathrm{O}(\nu$ and $\delta)$, whereas the peaks at 325 and $271 \mathrm{~cm}^{-1}$ are originated from bending frequencies of $\mathrm{O}-\mathrm{W}-\mathrm{O}$.

Further structural information of the catalysts is elucidated by X-ray diffraction (XRD) analysis in Fig. 1d. The characteristic Keggin structure peaks at $2 \theta=10.7^{\circ}, 15.3^{\circ}$, $24.9^{\circ}, 27.1^{\circ}, 31.5^{\circ}$ and $37.2^{\circ}$ correspond to HPW phase (PDF\#50-0304) (Qin et al. 2016). For $\mathrm{WO}_{3} / \mathrm{MMS}-500$ and $\mathrm{WO}_{3} / \mathrm{MMS}-600$, the characteristic diffraction peaks at $2 \theta$ $=23.7^{\circ}, 24.9^{\circ}, 34.4^{\circ}$ and $35.1^{\circ}$ are well consistent with the standard of $\mathrm{WO}_{3}$ phase (PDF\#43-1035) (Ciptonugroho et al. 2016; Hasan et al. 2012). Besides, the crystallinity of $\mathrm{WO}_{3}$ was improved with the rise of calcination temperature due to its increasing peak intensity of $\mathrm{WO}_{3}$. These results are in accordance with Raman analysis results.

The hysteresis loops of original $\mathrm{Fe}_{3} \mathrm{O}_{4}$, MNS, MMS and $\mathrm{WO}_{3}$ /MMS-500 were investigated to analyze superparamagnetic ability with superconductive quantum interference device (SQUID). As shown in Fig. 2, all of the samples show superparamagnetic behaviors because of no hysteresis in the hysteresis loop. The saturation magnetization values of $\mathrm{Fe}_{3} \mathrm{O}_{4}$ particles, $\mathrm{Fe}_{3} \mathrm{O}_{4} @ \mathrm{SiO}_{2}$, MMS and $\mathrm{WO}_{3} / \mathrm{MMS}-500$ are $47.87,6.71,2.31$ and $2.30 \mathrm{emu} \mathrm{g}^{-1}$, respectively. The $\mathrm{SiO}_{2}$ layer weakened the maximum saturation magnetization, but no saturation magnetization was changed when $\mathrm{WO}_{3}$ was embedded into the carrier. Therefore, the catalyst could be easily separated from the catalytic system by applying an external magnet field.

The $\mathrm{N}_{2}$ adsorption-desorption isotherms of the samples were investigated to study the mesoporous structure of the catalysts under different calcination temperature. The steep adsorption-desorption step was observed in the narrow relative pressure range of 0.4-1.0. As shown in Fig. 3, all of the samples present the typical Type IV isotherm, indicating the presence of mesopores. The textural properties and $\mathrm{BJH}$ pore size distribution analysis of the

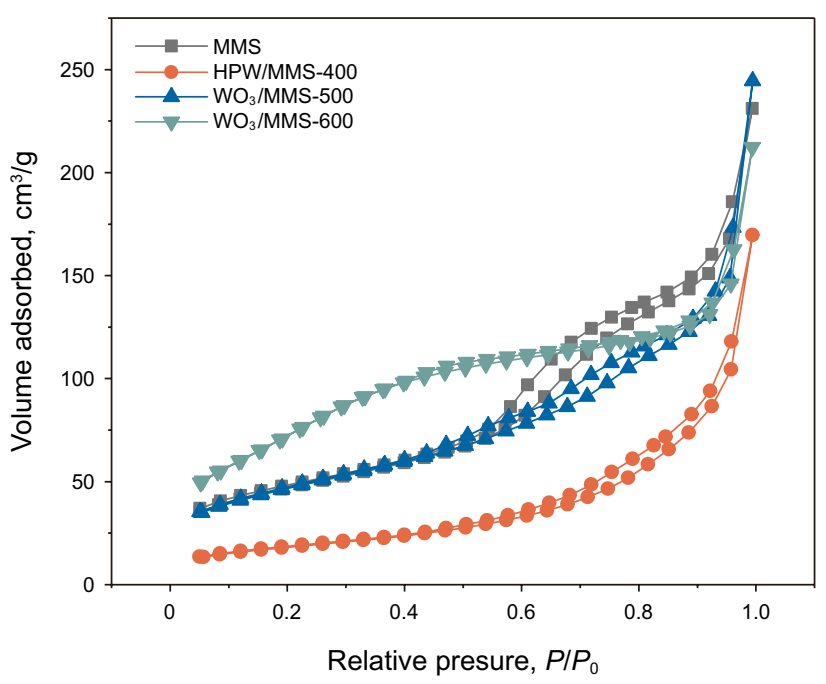

Fig. $3 \mathrm{~N}_{2}$ absorption/desorption isotherms of various samples
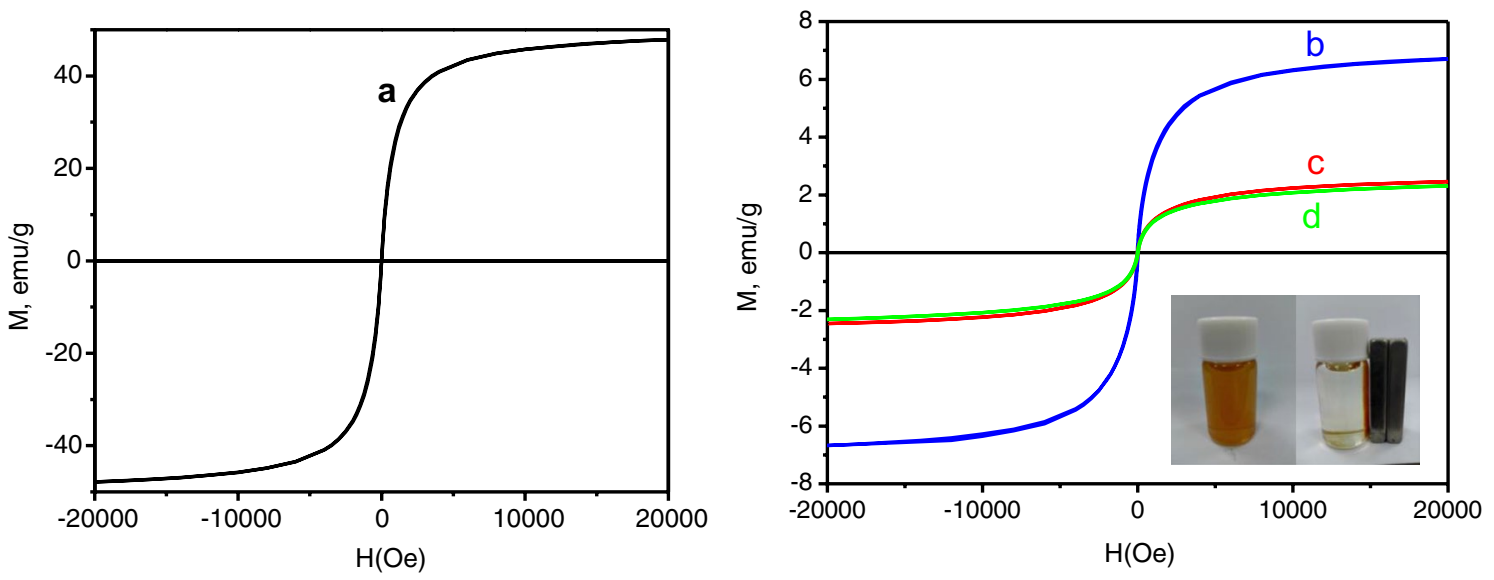

Fig. 2 Magnetic hysteresis loops of $\mathbf{a} \mathrm{Fe}_{3} \mathrm{O}_{4}$, b MNS, c MMS, and d $\mathrm{WO}_{3} / \mathrm{MMS}-500$ 
various samples are presented in Table 1 and Fig. S3. The Brunauer-Emmett-Teller (BET) surface area, pore volume and average pore size of MMS are calculated as $165 \mathrm{~m}^{2} \mathrm{~g}^{-1}$, $0.24 \mathrm{~m}^{3} \mathrm{~g}^{-1}$ and $6 \mathrm{~nm}$, respectively, suggesting highly porous structures. After HPW was loaded on MMS, the surface area and pore volume decreased, indicating that HPW was introduced into the channel. However, the surface area and increased to $167 \mathrm{~m}^{2} \mathrm{~g}^{-1}$ and pore volume decreased a little to $0.21 \mathrm{~m}^{3} \mathrm{~g}^{-1}$ for $\mathrm{WO}_{3} / \mathrm{MMS}-500$, which may mean the great dispersion of $\mathrm{WO}_{3}$. Compared with $\mathrm{WO}_{3} / \mathrm{MMS}-500, \mathrm{WO}_{3} /$ MMS-600 had the smaller pore size because the mesoporous structure was destroyed at the higher temperature. Therefore, $\mathrm{WO}_{3} / \mathrm{MMS}-500$ may be the best catalyst due to the synergetic effect of specific surface area and pore size.

To obtain the surface chemical states and the composition of $\mathrm{WO}_{3} / \mathrm{MMS}-500, \mathrm{X}$-ray photoelectron spectroscopy (XPS) was performed. As seen in Fig. 4, the elements O, W and $\mathrm{Si}$ are detected, illustrating that $\mathrm{WO}_{3}$ were successfully anchored on the surface of MMS. As expected, the element Fe cannot be identified because of the protection of silica layer. The $\mathrm{W} 4 f$ core-level spectra of $\mathrm{WO}_{3}$ / MMS-500 could be split into $4 f_{5 / 2}$ and $4 f_{7 / 2}$ peaks because of the spin-orbital coupling feature. The two peaks at 36.0 and $38.1 \mathrm{eV}$ are attributed to the typical $\mathrm{W}^{6+}$ (Xie et al. 2012).

Table 1 Textural properties of various samples

\begin{tabular}{llcll}
\hline Entry & Samples & $S_{\mathrm{BET}}, \mathrm{m}^{2} \mathrm{~g}^{-1}$ & $\begin{array}{l}\text { Pore vol- } \\
\text { ume, } \mathrm{cm}^{3}\end{array}$ & Pore size, $\mathrm{nm}$ \\
$\mathrm{g}^{-1}$ & & 165 & 0.25 & 6 \\
\hline 1 & MMS & 65 & 0.14 & 9 \\
2 & HPW/MMS-400 & 167 & 0.21 & 5 \\
3 & $\mathrm{WO}_{3} / \mathrm{MMS}-500$ & 167 & 0.21 & 3 \\
4 & $\mathrm{WO}_{3} / \mathrm{MMS}-600$ & 280 & & \\
\hline
\end{tabular}

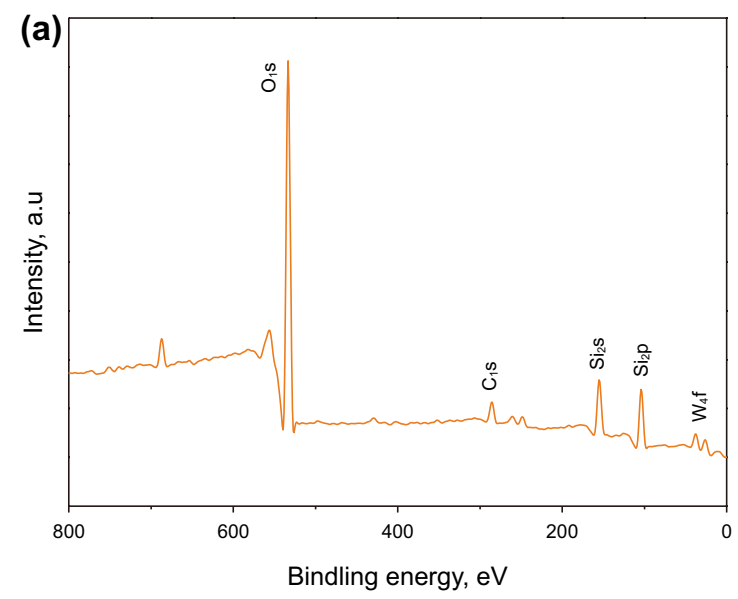

\subsection{Catalytic performances of different catalysts on DBT removal}

To understand the DBT removal efficiency of $\mathrm{WO}_{3} / \mathrm{MMS}$ 500 , various catalysts including MMS, the catalyst without mesoporous layer (denoted as $\mathrm{WO}_{3} / \mathrm{MNS}$ ), $\mathrm{WO}_{3} / \mathrm{MMS}-500$ and $\mathrm{WO}_{3}$ /MMS-600 were used for oxidation desulfurization process under the same reaction conditions in Fig. 5. The catalytic performances of the four catalysts were decreased in the following order: $\mathrm{WO}_{3} / \mathrm{MMS}-500>\mathrm{WO}_{3} / \mathrm{MMS}-600>$ $\mathrm{WO}_{3} / \mathrm{MNS}>\mathrm{MMS}$ and the corresponding desulfurization efficiency was $99.9 \%, 82.6 \%, 59.9 \%$ and $6.5 \%$, respectively. The above BET analysis elucidated the reason of the difference between the two catalysts $\mathrm{WO}_{3} / \mathrm{MMS}-500$ and $\mathrm{WO}_{3} /$ MMS-600. Although they had the similar mesoporous structure and the same active sites, the desulfurization efficiency

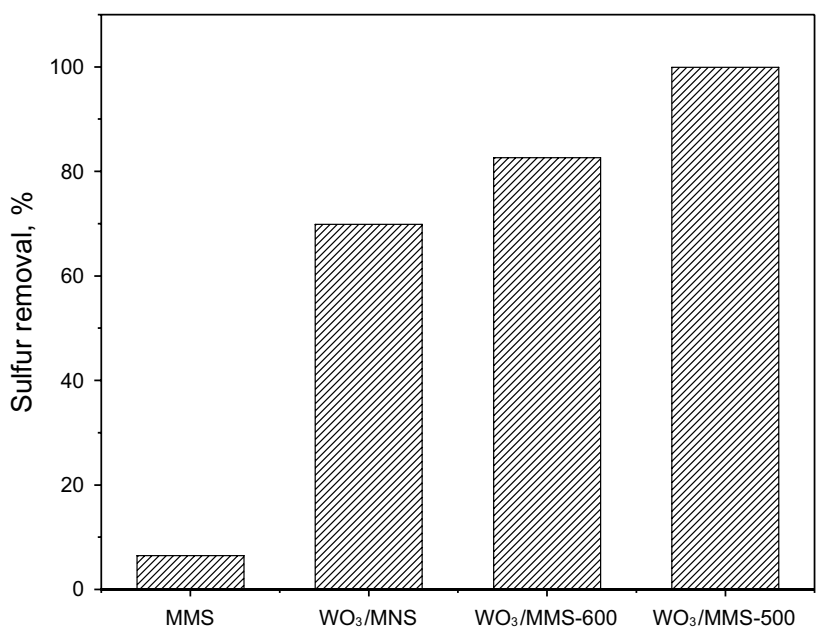

Fig. 5 Removal of DBT over different catalysts. Reaction conditions: $m$ (catalyst) $=0.01 \mathrm{~g}, T=120^{\circ} \mathrm{C}$, air flow $=100 \mathrm{~mL} / \mathrm{min}, V($ model oil) $=20 \mathrm{~mL}$, and $t=8 \mathrm{~h}$

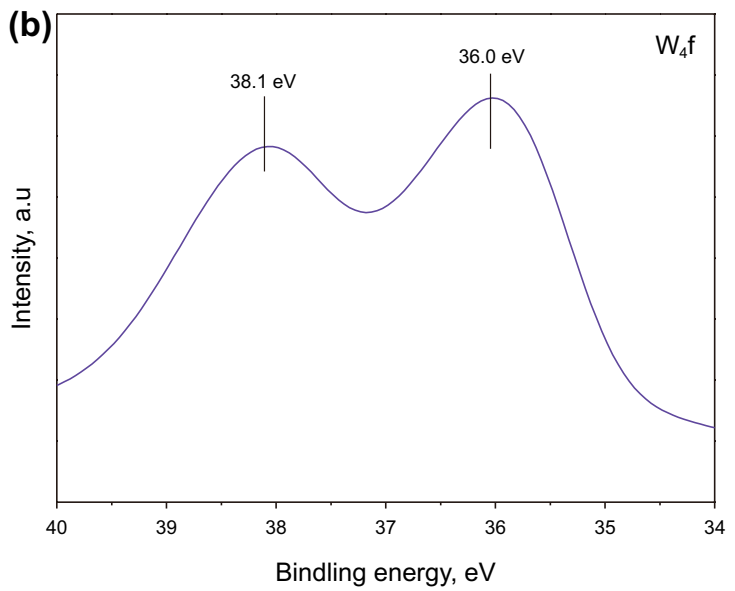

Fig. 4 a XPS spectra of $\mathrm{WO}_{3} / \mathrm{MMS}-500$ and $\mathbf{b} \mathrm{W} 4 \mathrm{f}$ core-level spectrum of $\mathrm{WO}_{3} / \mathrm{MMS}-500$ 
of $\mathrm{WO}_{3} / \mathrm{MMS}-600$ was lower than that of $\mathrm{WO}_{3} / \mathrm{MMS}-500$ due to the destroyed mesoporous structure at the higher temperature. Besides, MMS and $\mathrm{WO}_{3} / \mathrm{MNS}$ presented lower sulfur removal due to the lack of active components or mesoporous structure, further confirming the importance of the mesoporous structure and active sites.

\subsection{Effect of reaction temperature}

Reaction temperature is one of the most significant factor catalytic oxidation reactions. The desulfurization performance of DBT with an air flow rate of $100 \mathrm{~mL} / \mathrm{min}$ at different reaction temperatures is depicted in Fig. 6. When the reaction temperature was increased from $110{ }^{\circ} \mathrm{C}$ to $115^{\circ} \mathrm{C}$ and $120^{\circ} \mathrm{C}$, the sulfur removal was dramatically increased from $35.2 \%$ to $89.2 \%$ and $99.9 \%$ after 8 -h reaction. Generally, reaction rate is controlled by reaction temperature and a high temperature can accelerate the effective collision between catalyst, oxidant and substrate, thus leading to the higher DBT removal efficiency in the study. Therefore, the optimal reaction temperature for this oxidative desulfurization system was $120^{\circ} \mathrm{C}$. Although carbon nanotube (Zhang et al. 2014) and reduced graphene oxide (Gu et al. 2017) also showed high desulfurization efficiency, their reaction temperature was higher than $140{ }^{\circ} \mathrm{C}$. Hence, the reaction temperature in this study may decrease the energy consumption and desulfurization cost.

\subsection{Effect of substrate features on desulfurization}

There are various refractory sulfides in actual diesel oil including 4,6-DMDBT, 4-MDBT and DBT. Therefore, it is

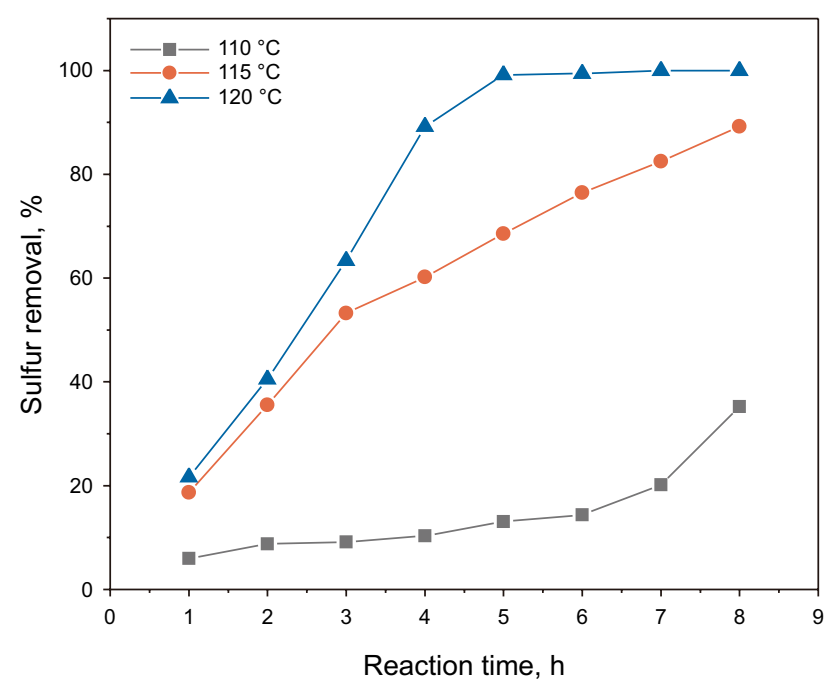

Fig. 6 Effects of different reaction temperatures on DBT removal. Reaction conditions: $m$ (catalyst) $=0.01 \mathrm{~g}$, air flow $=100 \mathrm{~mL} / \mathrm{min}$, and $V($ model oil $)=20 \mathrm{~mL}$ necessary to investigate the sulfur removal of different sulfur compounds in model oil. The removal efficiencies of different refractory sulfides are shown in Fig. 7. The desulfurization activity under the same reaction conditions decreased in the following order: DBT, 4-MDBT, 4,6-DMDBT and their sulfur removal rates reached 99.9, 98.2 and $92.3 \%$, respectively, after $8 \mathrm{~h}$. It might be interpreted by the negative effect of steric hindrance of the methyl in benzene ring (Li et al. 2016).

\subsection{Recycling of $\mathrm{WO}_{3} / \mathrm{MMS}-500$ catalyst}

To explore the stability and recovery of $\mathrm{WO}_{3}$ /MMS-500, the catalyst was separated from reaction system with an external magnet after the first recycling round. Then, it could be regenerated by washing with acetonitrile and dried in an oven at $80{ }^{\circ} \mathrm{C}$ for $4 \mathrm{~h}$ for the next use. Fresh model oil and oxidant were added for the next run under the same reaction conditions. The sulfur removals could reach 99.4, 97.6 and $84.8 \%$, respectively, in three recycling rounds (Fig. 8a). The recycled catalyst was gathered by a magnet to further explore its stability with Raman spectra. As seen from Fig. 8b, the fundamental structure of the catalyst still remained, but the spectrum of recycled catalyst showed lower intensity, which probably indicated the loss of active components after two recycling rounds. Compared with the fresh catalyst, about $10 \%$ of active components were lost after the reaction, as determined by ICP-AES. The possible reason was that partial active components could be fallen off in the acetonitrile washing process. However, the conversion of DBT in the three recycling rounds reached $99.9 \%, 97.8 \%$ and $92.3 \%$

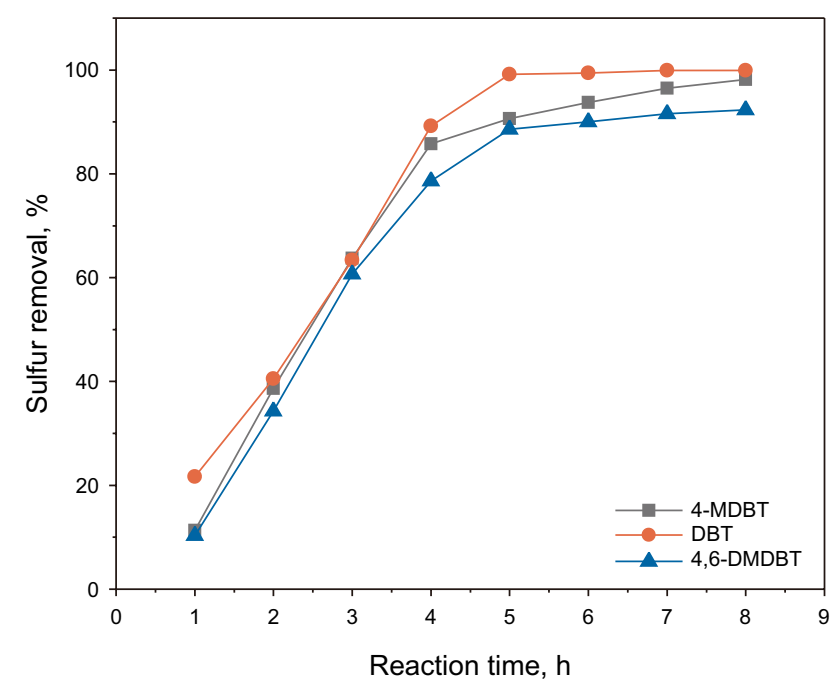

Fig. 7 Removal of different substrates in the desulfurization system. Reaction conditions: $m$ (catalyst) $=0.01 \mathrm{~g}, T=120{ }^{\circ} \mathrm{C}$, air flow $=$ $100 \mathrm{~mL} / \mathrm{min}$, and $V$ (model oil $)=20 \mathrm{~mL}$ 

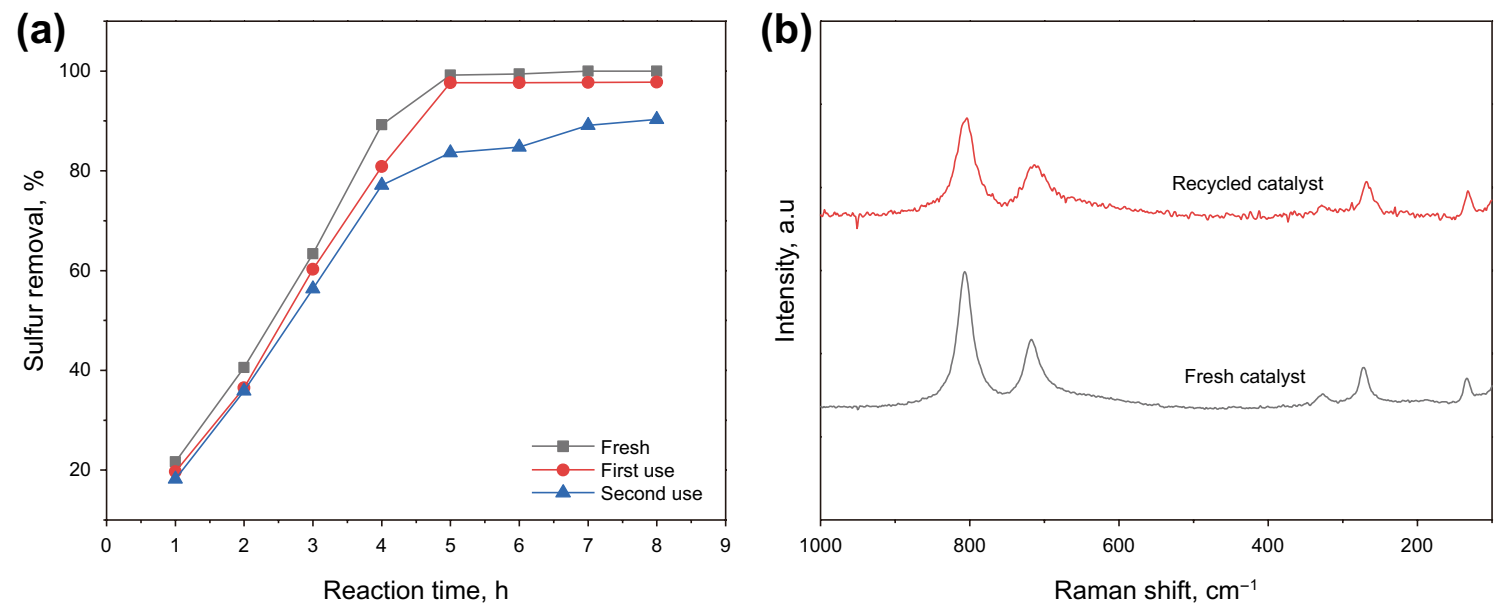

Fig. 8 a Recycling of $\mathrm{WO}_{3} / \mathrm{MMS}-500$ catalyst for DBT removal. b Raman spectra of fresh and recycled catalysts

after $8 \mathrm{~h}$, indicating that the recycled catalyst presented the relatively good recovery ability.

\subsection{Possible reaction mechanism}

In the presence of $\mathrm{WO}_{3}$-based catalyst, superoxide racial $\left(\mathrm{O}_{2}^{-}\right)$or peroxide are possibly produced as the active species in the reaction process. To verify this assumption, selective quenching experiments are investigated in Fig. 9a with TBA and $\mathrm{BQ}$ as $\mathrm{HO}^{-}$and $\mathrm{O}_{2}^{--}$quenchers (Gomez-Paricio et al. 2016). The sulfur removal was only decreased by $0.6 \%$ after the addition of TBA, but it was dramatically decreased from $99.9 \%$ to $3.1 \%$ after the addition of BQ. It can be deduced that $\mathrm{O}_{2}^{--}$may be the main oxygen active species. To further understand the oxidation process, the catalyst $\mathrm{WO}_{3} / \mathrm{MMS}-500$ was treated in decalin at $120{ }^{\circ} \mathrm{C}$ under the air flow rate of $100 \mathrm{~mL} / \mathrm{min}$. Then, the fresh catalyst and treated catalyst were characterized by FT-IR spectra in Fig. 9b. The stretching vibration peak of $\mathrm{W}-\mathrm{O}-\mathrm{W}$ at $815 \mathrm{~cm}^{-1}$ shifted to $805 \mathrm{~cm}^{-1}$, suggesting the formation of peroxide species, such as $\mathrm{W}-\mathrm{O}-\mathrm{O}-\mathrm{W}$ or $\mathrm{W}-\mathrm{O}-\mathrm{O}$. This peroxide could also serve as the oxidant for sulfide oxidation ( $\mathrm{Li}$ et al. 2017a, b). The above analysis indicated that the possible desulfurization mechanism of the oxidation process might involve the following procedures in Scheme 1. First, oxygen molecules were absorbed onto the surface of the catalyst to form $\mathrm{W}^{6+}-\mathrm{O}_{2}$ species. Then, the superoxide species $\left(\mathrm{W}^{6+}-\mathrm{O}_{2}^{-}\right)$and tungsten peroxide were produced, which could oxidize sulfides to sulfones.
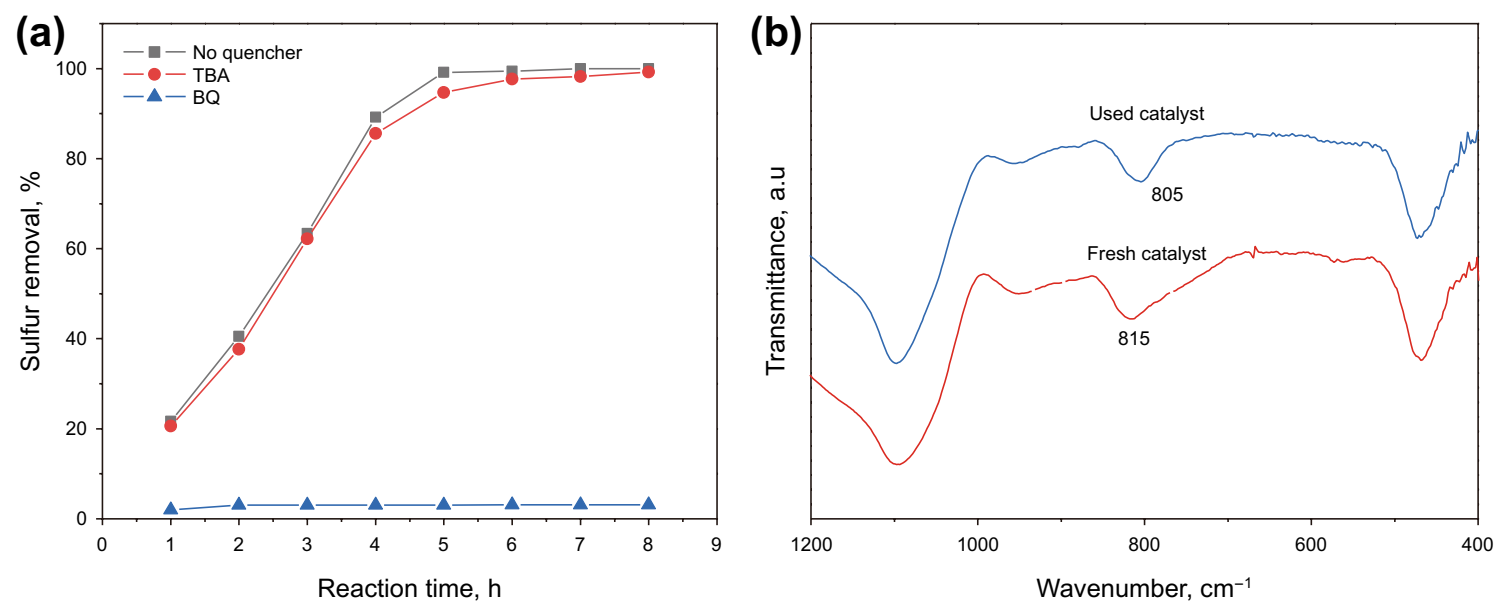

Fig. 9 a Selective quenching experiments with BQ or TBA. b FT-IR spectra of fresh catalyst and used catalyst after interaction with $\mathrm{O}_{2}$ 


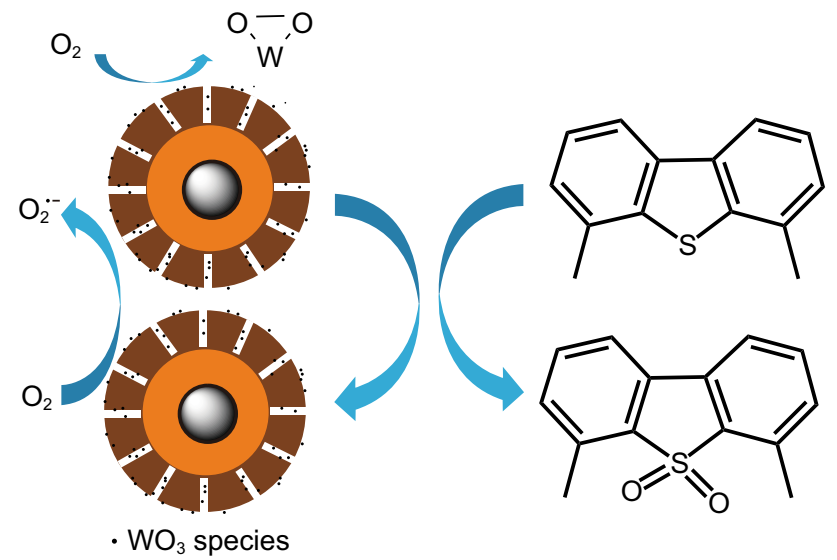

Scheme 1 Proposed reaction mechanism for aerobic oxidation of sulfur compounds over $\mathrm{WO}_{3} / \mathrm{MMS}-500$

\section{Conclusion}

In the study, magnetic mesoporous core-shell structure catalysts were successfully prepared. The mesoporous structure of MMS was maintained after the introduction of tungsten species. Using $\mathrm{WO}_{3} / \mathrm{MMS}-500$ as a catalyst and $\mathrm{O}_{2}$ as an oxidant, the removal of DBT reached up to $99.9 \%$ at $120^{\circ} \mathrm{C}$. The removal rates of two other sulfides (4-MDBT and 4,6DMDBT) were got to $98.2 \%$ and $92.3 \%$, respectively. Additionally, the catalyst could be reused easily with an external magnet. The possible reaction mechanism was explored by selective quenching experiments and FT-IR spectra. $\mathrm{O}_{2}^{--}$and tungsten peroxide might be the active oxygen species.

Acknowledgements This work was financially supported by the National Natural Science Foundation of China (Nos. 21978119, 21576122, and 21766007), and a Project Funded by the Priority Academic Program Development of Jiangsu Higher Education Institutions. W. J. appreciates the support of the Jiangsu Government Scholarship for oversea studies.

Open Access This article is licensed under a Creative Commons Attribution 4.0 International License, which permits use, sharing, adaptation, distribution and reproduction in any medium or format, as long as you give appropriate credit to the original author(s) and the source, provide a link to the Creative Commons licence, and indicate if changes were made. The images or other third party material in this article are included in the article's Creative Commons licence, unless indicated otherwise in a credit line to the material. If material is not included in the article's Creative Commons licence and your intended use is not permitted by statutory regulation or exceeds the permitted use, you will need to obtain permission directly from the copyright holder. To view a copy of this licence, visit http://creativecommons.org/licenses/by/4.0/.

\section{References}

Acharyya SS, Ghosh S, Bal R. Nanoclusters of $\mathrm{Cu}$ (II) supported on nanocrystalline $\mathrm{W}(\mathrm{VI})$ oxide: a potential catalyst for singlestep conversion of cyclohexane to adipic acid. Green Chem. 2015;17(6):3490-9. https://doi.org/10.1039/c5gc00379b.

Afsharpour M, Amraee AR. Synthesis of bio-inspired N-doped sic and investigation of its synergetic effects on Mo catalysts in oxidative desulfurization reaction. Mol Catal. 2017;436:285-93. https://doi. org/10.1016/j.mcat.2017.04.029.

Behnejad B, Abdouss M, Tavasoli A. Comparison of performance of Ni-Mo/-alumina catalyst in HDS and HDN reactions of main distillate fractions. Pet Sci. 2019;16(3):645-56. https://doi. org/10.1007/s12182-019-0319-5.

Bhadra BN, Jhung SH. Oxidative desulfurization and denitrogenation of fuels using metal-organic framework-based/-derived catalysts. Appl Catal B. 2019;259:118021.

Bryzhin AA, Gantman MG, Buryak AK, Tarkhanova IG. Bronsted acidic SILP-based catalysts with $\mathrm{H}_{3} \mathrm{PMo}_{12} \mathrm{O}_{40}$ or $\mathrm{H}_{3} \mathrm{PW}_{12} \mathrm{O}_{40}$ in the oxidative desulfurization of fuels. Appl Catal B. 2019. https ://doi.org/10.1016/j.apcatb.2019.117938.

Ciptonugroho W, Al-Shaal MG, Mensah JB, Palkovits R. One pot synthesis of $\mathrm{WO}_{\mathrm{x}} /$ mesoporous $-\mathrm{ZrO}_{2}$ catalysts for the production of levulinic-acid esters. J Catal. 2016;340:17-29. https://doi. org/10.1016/j.jcat.2016.05.001.

Deng Y, Qi D, Deng C, Zhang X, Zhao D. Superparamagnetic highmagnetization microspheres with an $\mathrm{Fe}_{3} \mathrm{O}_{4} @ \mathrm{SiO}_{2}$ core and perpendicularly aligned mesoporous $\mathrm{SiO}_{2}$ shell for removal of microcystins. J Am Chem Soc. 2008;130(1):28-9. https://doi. org/10.1021/ja0777584.

Ding J, Liu Q, Zhang Z, Liu X, Zhao J, Cheng S, et al. Carbon nitride nanosheets decorated with $\mathrm{WO}_{3}$ nanorods: ultrasonic-assisted facile synthesis and catalytic application in the green manufacture of dialdehydes. Appl Catal B. 2015;165:511-8. https://doi. org/10.1016/j.apcatb.2014.10.037.

Gao LG, Li HX, Song XL, Li WL, Ma XR. Degradation of benzothiophene in diesel oil by LaZnAl layered double hydroxide: photocatalytic performance and mechanism. Pet Sci. 2019;16(1):173-9. https://doi.org/10.1007/s12182-018-0285-3.

Gomez-Paricio A, Santiago-Portillo A, Navalon S, Concepcion P, Alvaro M, Garcia H. MIL-101 promotes the efficient aerobic oxidative desulfurization of dibenzothiophenes. Green Chem. 2016;18(2):508-15. https://doi.org/10.1039/c5gc00862j.

Gu QQ, Wen GD, Ding YX, Wu KH, Chen CM, Su DS. Reduced graphene oxide: a metal-free catalyst for aerobic oxidative desulfurization. Green Chem. 2017;19(4):1175-81. https://doi. org/10.1039/c6gc02894b.

Hamid SBA, Daud NA, Suppiah DD, Yehya WA, Sudarsanam P, Bhargava SK. Catalytic dehydration of glycerol to acrolein over $\mathrm{M}_{2.5} \mathrm{H}_{0.5} \mathrm{PW}_{12} \mathrm{O}_{40}(\mathrm{M}=\mathrm{Cs}, \mathrm{Rb}$ and $\mathrm{K})$ phosphotungstic acids: effect of substituted alkali metals. Polyhedron. 2016;120:15461. https://doi.org/10.1016/j.poly.2016.08.027.

Hao L, Wang M, Shan W, Deng C, Ren W, Shi Z, et al. L-prolinebased deep eutectic solvents (DESs) for deep catalytic oxidative desulfurization (ODS) of diesel. J Hazard Mater. 2017;339:21622. https://doi.org/10.1016/j.jhazmat.2017.06.050.

Hasan Z, Jeon J, Jhung SH. Oxidative desulfurization of benzothiophene and thiophene with $\mathrm{WO}_{\mathrm{x}} / \mathrm{ZrO}_{2}$ catalysts: effect of calcination temperature of catalysts. J Hazard Mater. 2012;205206:216-21. https://doi.org/10.1016/j.jhazmat.2011.12.059.

Jiang W, Dong L, Li H, Jia H, Zhu LH, Zhu WS, et al. Magnetic supported ionic liquid catalysts with tunable pore volume for enhanced deep oxidative desulfurization. J Mol Liq. 2019a;274:293-9. https://doi.org/10.1016/j.molliq.2018.10.069. 
Jiang W, Jia H, Fan X, Dong L, Guo T, Zhu L, et al. Ionic liquid immobilized on magnetic mesoporous microspheres with rough surface: application as recyclable amphiphilic catalysts for oxidative desulfurization. Appl Surf Sci. 2019b;484:1027-34. https ://doi.org/10.1016/j.apsusc.2019.03.341.

Jiang W, Jia H, Li H, Zhu L, Tao R, Zhu W, et al. Boric acid-based ternary deep eutectic solvent for extraction and oxidative desulfurization of diesel fuel. Green Chem. 2019c;21(11):3074-80. https://doi.org/10.1039/C9GC01004A.

Jiang W, Jia H, Zheng Z, Zhu L, Dong L, Liu W, et al. Catalytic oxidative desulfurization of fuels in acidic deep eutectic solvents with $\left[\left(\mathrm{C}_{6} \mathrm{H}_{13}\right)_{3} \mathrm{P}\left(\mathrm{C}_{14} \mathrm{H}_{29}\right)\right]_{3} \mathrm{PMo}_{12} \mathrm{O}_{40}$ as a catalyst. Pet Sci. 2018;15(4):841-8. https://doi.org/10.1007/s12182-018-0263-9.

Jiang W, Xiao J, Dong L, Wang C, Li H, Luo Y, et al. Polyoxometalate-based poly(ionic liquid) as a precursor for superhydrophobic magnetic carbon composite catalysts toward aerobic oxidative desulfurization. ACS Sustain Chem Eng. 2019d;7(18):15755-61. https://doi.org/10.1021/acssuschem eng.9b04026.

Jiang W, Zhu K, Li H, Zhu L, Hua M, Xiao J, et al. Synergistic effect of dual Brønsted acidic deep eutectic solvents for oxidative desulfurization of diesel fuel. Chem Eng J. 2020;394:124831. https ://doi.org/10.1016/j.cej.2020.124831.

Lü H, Zhang Y, Jiang Z, Li C. Aerobic oxidative desulfurization of benzothiophene, dibenzothiophene and 4,6-dimethyldibenzothiophene using an anderson-type catalyst $\left[\left(\mathrm{C}_{18} \mathrm{H}_{37}\right)_{2} \mathrm{~N}\left(\mathrm{CH}_{3}\right)_{2}\right]_{5}\left[\mathrm{IMo}_{6} \mathrm{O}_{24}\right]$. Green Chem. 2010;12(11):1954. https://doi.org/10.1039/c0gc0 0271b.

Li H, Zhu W, Zhu S, Xia J, Chang Y, Jiang W, et al. The selectivity for sulfur removal from oils: an insight from conceptual density functional theory. AIChE J. 2016;62(6):2087-100. https://doi. org/10.1002/aic.15161.

Li S-W, Li J-R, Gao Y, Liang L-L, Zhang R-L, Zhao J-S. Metal modified heteropolyacid incorporated into porous materials for a highly oxidative desulfurization of DBT under molecular oxygen. Fuel. 2017a;197:551-61. https://doi.org/10.1016/j.fuel.2017.02.064.

Li S-W, Li J-R, Jin Q-P, Yang Z, Zhang R-L, Gao R-M, et al. Preparation of mesoporous Cs-POM@MOF-199@MCM-41 under two different synthetic methods for a highly oxidesulfurization of dibenzothiophene. J Hazard Mater. 2017b;337:208-16. https:// doi.org/10.1016/j.jhazmat.2017.04.037.

Li S-W, Yang Z, Gao R-M, Zhang G, Zhao J-S. Direct synthesis of mesoporous SRL-POM@MOF-199@MCM-41 and its highly catalytic performance for the oxidesulfurization of DBT. Appl Catal B. 2018;221:574-83. https://doi.org/10.1016/j.apcat b.2017.09.044.

Li XL, Gu YL, Chu HQ, Ye G, Zhou W, Xu W, et al. MFM-300(V) as an active heterogeneous catalyst for deep desulfurization of fuel oil by aerobic oxidation. Appl Catal A. 2019. https://doi. org/10.1016/j.apcata.2019.117152.

Lü H, Ren W, Liao W, Chen W, Li Y, Suo Z. Aerobic oxidative desulfurization of model diesel using a B-type anderson catalyst $\left[\left(\mathrm{C}_{18}\right.\right.$ $\left.\left.\mathrm{H}_{37}\right)_{2} \mathrm{~N}\left(\mathrm{CH}_{3}\right)_{2}\right]_{3} \mathrm{Co}(\mathrm{OH})_{6} \mathrm{Mo}_{6} \mathrm{O}_{18}$ center dot $3 \mathrm{H}_{2} \mathrm{O}$. Appl Catal B. 2013;138:79-83. https://doi.org/10.1016/j.apcatb.2013.02.034.

Lu HY, Gao JB, Jiang ZX, Yang YX, Song B, Li C. Oxidative desulfurization of dibenzothiophene with molecular oxygen using emulsion catalysis. Chem Commun. 2007;2:150-2. https://doi. org/10.1039/b610504a.

Luo J, Chao YH, Tang ZY, Hua MQ, Li XW, Wei YC, et al. Design of lewis acid centers in bundlelike boron nitride for boosting adsorptive desulfurization performance. Ind Eng Chem Res. 2019;58(29):13303-12. https://doi.org/10.1021/acs.iecr.9b01745.

Lv G, Deng S, Yi Z, Zhang X, Wang F, Li H, et al. One-pot synthesis of framework w-doped TS-1 zeolite with robust lewis acidity for effective oxidative desulfurization. Chem Commun. 2019;55(33):4885-8. https://doi.org/10.1039/C9CC00715F.

Ma T, Ding J, Shao R, Xu W, Yun Z. Dehydration of glycerol to acrolein over Wells-Dawson and Keggin type phosphotungstic acids supported on MCM-41 catalysts. Chem Eng J. 2017;316:797-806. https://doi.org/10.1016/j.cej.2017.02.018.

Mehmood F, Iqbal J, Jan T, Mansoor Q. Structural, raman and photoluminescence properties of fe doped $\mathrm{WO}_{3}$ nanoplates with anti cancer and visible light driven photocatalytic activities. J Alloys Compd. 2017;728:1329-37. https://doi.org/10.1016/j.jallc om.2017.08.234.

Qin L, Zheng Y, Li D, Zhou Y, Zhang L, Zuhra Z. Phosphotungstic acid immobilized on amino functionalized spherical millimeter-sized mesoporous $\gamma-\mathrm{Al}_{2} \mathrm{O}_{3}$ bead and its superior performance in oxidative desulfurization of dibenzothiophene. Fuel. 2016;181:827-35. https://doi.org/10.1016/j.fuel.2016.05.063.

Ren XL, Liu ZW, Dong L, Miao G, Liao N, Li Z, et al. Dynamic catalytic adsorptive desulfurization of real diesel over ultra-stable and low-cost silica gel-supported $\mathrm{TiO}_{2}$. AIChE J. 2018;64(6):2146-59. https://doi.org/10.1002/aic.16055.

Shen C, Wang YJ, Xu JH, Luo GS. Synthesis of TS-1 on porous glass beads for catalytic oxidative desulfurization. Chem Eng J. 2015;259:552-61. https://doi.org/10.1016/j.cej.2014.08.027.

Shen D, Dai Y, Han J, Gan L, Liu J, Long M. A nanocellulose template strategy for the controllable synthesis of tungsten-containing mesoporous silica for ultra-deep oxidative desulfurization. Chem Eng J. 2018;332:563-71. https://doi.org/10.1016/j. cej.2017.09.087.

Shi M, Zhang D, Yu X, Li Y, Wang X, Yang W. Deep oxidative desulfurization catalyzed by $\left(\mathrm{NH}_{4}\right)_{5} \mathrm{HPV}_{8} \mathrm{Mo}_{4} \mathrm{O}_{40}$ using molecular oxygen as an oxidant. Fuel Process Technol. 2017;160:136-42. https://doi.org/10.1016/j.fuproc.2017.02.038.

Smolders S, Willhammar T, Krajnc A, Sentosun K, Wharmby MT, Lomachenko KA, et al. A titanium(IV)-based metal-organic framework featuring defect-rich Ti-O sheets as an oxidative desulfurization catalyst. Angew Chem Int Ed. 2019;58(27):9160-5. https://doi.org/10.1002/anie.201904347.

Song Z, Yu D, Zeng Q, Zhang J, Cheng H, Chen L, et al. Effect of water on extractive desulfurization of fuel oils using ionic liquids: a COSMO-RS and experimental study. Chin J Chem Eng. 2017;25(2):159-65. https://doi.org/10.1016/j.cjche.2016.08.029.

Sun SH, Zeng H, Robinson DB, Raoux S, Rice PM, Wang SX, et al. Monodisperse $\mathrm{MFe}_{2} \mathrm{O}_{4}(\mathrm{M}=\mathrm{Fe} \mathrm{Co}, \mathrm{Mn})$ nanoparticles. J Am Chem Soc. 2004;126(1):273-9. https://doi.org/10.1021/ja038 0852.

Tang NF, Zhang YN, Lin F, Lu HY, Jiang ZX, Li C. Oxidation of dibenzothiophene catalyzed by $\left[\mathrm{C}_{8} \mathrm{H}_{17} \mathrm{~N}\left(\mathrm{CH}_{3}\right)_{3}\right]_{3} \mathrm{H}_{3} \mathrm{~V}_{10} \mathrm{O}_{28}$ using molecular oxygen as oxidant. Chem Commun. 2012;48(95):11647-9. https://doi.org/10.1039/c2cc36482d.

Wang F, Wang G, Sun W, Wang T, Chen X. Metallophthalocyanine functionalized magnetic mesoporous silica nanoparticles and its application in ultrasound-assisted oxidation of benzothiophene. Microporous Mesoporous Mater. 2015;217:203-9. https://doi. org/10.1016/j.micromeso.2015.06.038.

Wang Q, Zhang T, Zhang SL, Fan YC, Chen B. Extractive desulfurization of fuels using trialkylamine-based protic ionic liquids. Sep Purif Technol. 2020;231:115923. https://doi.org/10.1016/j.seppu r.2019.115923.

Wu P, Dai B, Chao Y, Wu Y, Jiang W, Li C, et al. Graphene-like boron nitride anchored bronsted acid ionic liquids as metal-free catalyst for advanced oxidation process. Mol Catal. 2017;436:53-9. https ://doi.org/10.1016/j.mcat.2017.04.008.

Wu P, Zhu W, Dai B, Chao Y, Li C, Li H, et al. Copper nanoparticles advance electron mobility of graphene-like boron nitride 
for enhanced aerobic oxidative desulfurization. Chem Eng J. 2016;301:123-31. https://doi.org/10.1016/j.cej.2016.04.103.

Xie FY, Gong L, Liu X, Tao YT, Zhang WH, Chen SH, et al. XPS studies on surface reduction of tungsten oxide nanowire film by $\mathrm{Ar}^{+}$bombardment. J Electron Spectrosc Relat Phenom. 2012;185(3):112-8. https://doi.org/10.1016/j.elspec.2012.01.004.

Xun S, Zhu W, Chang Y, Li H, Zhang M, Jiang W, et al. Synthesis of supported $\mathrm{SiW}_{12} \mathrm{O}_{40}$-based ionic liquid catalyst induced solvent-free oxidative deep-desulfurization of fuels. Chem Eng J. 2016;288:608-17. https://doi.org/10.1016/j.cej.2015.12.005.

Xun SH, Jiang W, Guo T, He MQ, Ma RL, Zhang M, et al. Magnetic mesoporous nanospheres supported phosphomolybdate-based ionic liquid for aerobic oxidative desulfurization of fuel. J Colloid Interface Sci. 2019;534:239-47. https://doi.org/10.1016/j. jcis.2018.08.115.

Zhang M, Wang M, Yang JP, Li HP, Liu JQ, Chen X, et al. Polyoxometalate-based silica-supported ionic liquids for heterogeneous oxidative desulfurization in fuels. Pet Sci. 2018;15(4):882-9. https ://doi.org/10.1007/s12182-018-0267-5.
Zhang W, Zhang H, Xiao J, Zhao Z, Yu M, Li Z. Carbon nanotube catalysts for oxidative desulfurization of a model diesel fuel using molecular oxygen. Green Chem. 2014;16(1):211-20. https://doi. org/10.1039/c3gc41106k.

Zhang Z, Zhang F, Zhu Q, Zhao W, Ma B, Ding Y. Magnetically separable polyoxometalate catalyst for the oxidation of dibenzothiophene with $\mathrm{H}_{2} \mathrm{O}_{2}$. J Colloid Interface Sci. 2011;360(1):189-94. https://doi.org/10.1016/j.jcis.2011.04.045.

Zhao R, Li X, Su J, Gao X. Preparation of $\mathrm{WO}_{3} / \mathrm{g}-\mathrm{C}_{3} \mathrm{~N}_{4}$ composites and their application in oxidative desulfurization. Appl Surf Sci. 2017a;392:810-6. https://doi.org/10.1016/j.apsusc.2016.08.120.

Zhao R, Wang J, Zhang D, Sun Y, Han B, Tang N, et al. Deep catalytic oxidative desulfurization of model fuel based on modified iron porphyrins in ionic liquids: anionic ligand effect. ACS Sustain Chem Eng. 2017b;5(3):2050-5. https://doi.org/10.1021/acssu schemeng.6b02916. 